\title{
Muslim Community: the Living Fossils of the Chang'an Silk Road
}

\author{
Li Yinjin \\ Institute of Media, Xi'an Pei Hua College, \\ Xi'an China, 7101125 \\ e-mail: $1571891451 @ q q . c o m$
}

\author{
Wang Jing \\ Institute of Media, Xi'an Pei Hua College, \\ Xi'an China, 7101125
}

\begin{abstract}
In the corner, the northwestern part of the ancient city, Xi'an in China, west of the West Street in Xi'an Qiao Zi Kou, Guang Ji Street East, there are about 300,000 Muslim compatriots living in the area, commonly referred to by locals as "Hui Fang(Muslim Community)". Muslim culture and atmosphere are rich here, and it builds a beautiful scenery for the ancient city. Through the formation and cultural convergence of "muslim community", this article explores its formation of common culture and common psychological quality in the long historical development, under the background of multi-ethnic communion, traces its formation as the origin of the Silk Road, the historical value and cultural significance of living fossils.
\end{abstract}

Keywords-Hui Fang; Muslim Community; Silk Road; Cultural; Living Fossil

\section{INTRODUCTION}

"Fang" originated from the Tang Dynasty. It was a division of the Tang Dynasty. As the starting point of the Silk Road, Tang Chang'an accommodated a large number of ancient Persian and Sogdian immigrants from West Asia and Central Asia. With the influx of a large number of these immigrants, Islam also began spread in china. For the sake ofreligious activities and daily life, the ancient Persian and Sogdiandwelt around the mosque. This layout has been spreading from Islam to China till now. Each mosque forms a "Fang." "Fang Shang ren" is a cordial appellation in Xi'an to Muslim compatriots who believe in Islam. This living place is called "Hui Fang".

On the huge concept map of historic and synchronic intertwining of "Hui Fang" in Xi'an, concept travel, historical intertextuality and cultural wrestling of Xi'an Hui Fang have become the focus of academic research. Throughout the process of the formation of Hui Hui in Xi'an, the most important point is actually manifested in the common cultural common psychological quality. Tang Chang'an ,as the starting point of the Silk Road, accommodated a large number of ancient Persian, Sogdian immigrants from West Asia, Central Asia, most of them fled to chang'an. There are also Arabs who took the business with Tang Dynasty, and other ethnic minorities that were defeated by Tang.

Some experts think that to study the origin of Hui Muslims in Xi'an Hui Autonomous Region, the Persian people is the necessary topic. From the Persian language commonly used by the Hui people, their Persian cultural background can be seen. The Hui dialect in Xi'an , based on the Guan zhong dialect of the Han nationality, absorbs other national languages and foreign words, converges to form a special dialect. It is mainly used in the interior of the Hui people in Xi'an. A special branch of the Guanzhong dialect lies in the Hui ethnic dialect in Xi'an because of its distinct characteristics of the Hui ethnic group in Xi'an. The language retains the Arabic language, a large number of Persian vocabularies, Some Uighur, ancient vernacular and other words. Word formation and voice are also different from the Guanzhong dialect. The formation of the language is a long process. At the same time, it is an important symbol of the cultural prosperity and national integration of Chang'an which is the birthplace of the silk road. Under the background of multi-ethnic integration, the "Hui Fang", as a living fossil of the silk road, presents a specific historical value and cultural significance from the perspective of historical features and ethnic integration. 


\section{HISTORICAL LINEAGE AND LANGUAGE CHANGES}

Faced with the phenomenon of "Hui Fang" in the multi-ecological environment of historical context, it is of great significance to promote the integration of ethnic cultures and interdisciplinary research.

First, the Chang'an Muslims, which began in the Arabian Peninsula six years after the Sui Dynasty (AD 610) and quickly spread to China. In the Old Tang Book IV, the first envoy sent by Caliph Eman was included. Since China and Albania had land and sea traffic 500 years before Islam was preached, people's communication was earlier than that of the Old Tang Dynasty recorded. This shows that China has had frequent contacts with Arabs, Persia and other countries. There are not many Muslims living in China.

Second, Xi'an "Hui Fang" shows the reliability of the time dimension besides the subjectivity of the production dimension. It can be seen from the Tang Dynasty that there was a phenomenon of intermarriage between Muslims and the Han nationality. Under the background of multi-ethnic marriages ,the development trend of Xi'an" Hui Fang ",it has moved further toward another dimension.

It is undeniable that the Hui language as a common language of "living fossils" is a quite significant area of research. After more than a thousand years of development, the Hui people have already formed their own common communicative tool (language) - Hui language. And the Hui dialect in Xi'an has another notable characteristic. It takes Shaanxi Guanzhong dialect as the main body, absorbs other national languages and foreign words. At the same time,the self-made vocabulary, converges and condenses a special dialect, it is mainly used in Xi'an Hui Fang.

\section{Alternation AND CULTURAL CHANGE}

The birth and evolution of "Hui Fang" in Xi'an is related to the profound social and cultural changes. The origin of Hui Hui in Xi'an is extremely complicated. According to the preliminary investigation, the sources and development of the Hui in Xi'an experienced three periods: the Tang and Song dynasties (mainly the Tang dynasties), the Yuan Dynasty, the Ming Dynasty.
Just as the economic life of the Hui nationality influenced by the productive forces and the relations of production, in the feudal society of the Han nationality in China, it is inevitable that they will accept the influence of the Han nationality in cultural life. They should stand on their own feet, seek development, learn the Han culture, adapt to the social life of Han Chinese. Hui nationality is rich in wisdom and good at learning. The development of Hui culture has been closely linked with the study and absorption of Han culture from the very beginning. Only in this way can we enrich and develop our own culture. At this point, the Hui nationality in Xi'an officially appeared as a ethnic group. Most of them still live in Xi'an now.

Historically, most Muslims in Guang dong from Sea, and Muslims in Xi'an Hui Fang are mostly along the "Silk Road", riding camels, came from the land. At that time, Guang dong had a shipbuilding division that managed foreign trade; there was a Honglu special reception hall in Chang'an, which specially received the surrounding ethnic minorities and foreign diplomatic envoys. Ad the capital, Chang'an was the largest international city in the world at the time.

Due to the internal turmoil in the Arab caliphate and the continuous revolt of all ethnic groups in Central Asia, many Muslims migrated to various parts of the Central Plains and some lived in Chang'an. This became one of the sources of the Hui ancestors of the Hui Nationality in the early days of Xi'an.

Although the Silk Road is the product of the common promotion of economic and trade developments along the line, many people think that Zhang Qian of China twice crossed the Western Regions, opened up a new era of the exchange. It successfully opened the last bead curtain between East and West.

Since then, this route has been stepped on as a "national highway", and envoys, businessmen, and missionaries from all over the country are opening up along the path. Up to the kings and nobles, down to beggars prisoners, in this way, have left their own footprint. After several centuries of continuous efforts, the Silk Road has spread westward to the Mediterranean and has become a road for the economic and cultural exchanges between Asia and European countries. 
Thus, it can be seen that Xi'an's "HuiFang", a long-established new ethnic community formed on the vast land of China, is composed of ethnic people from all over the world who believe in Islam. In the long history of development, they have absorbed and fused many kinds Ethnic composition and gradually formed. In its formation and development, unlike other ethnic groups, it is not formed through the integration and integration of certain clans and tribes, and does not have the unity of ethnicity in forming ethnic groups.

The ethnic origin of the Hui nationality is a pluralistic combination of indigenous and non-indigenous people both ethnicly and racially. The occurrence of ethnic origin also has its own time sequence, which makes the Hui ethnic groups in different regions have not exactly the same. It can be said that the Silk Road has created such a new cultural area as Xi'an "Hui Fang". Xi'an "HuiFang" is also a cultural "living fossil" of the origin of the Chang'an Silk Road.

\section{REFERENCE}

[1] LuJing Research on the influence and social identification of Xi'an Hui Fang dietary culture < Journal of Nanning College for Vocational Technology> 2012.02

[2] LiJianbiao. Significance and value of national historic district protection-Xi'an Hui Fang reconstruction <Urban issues> 2010.05

[3] HappyHappy's blog A trip to Xi'an (Hui Fang's customs) 2009.01.01 04:12:19

[4] The interview of Ma Xifeng( associate professor,the Hui nationality, xi'an peihua university)2017.11.10

[5] The history of Xi'an Hui Fang, Collection of literature and history of Xi'an CPPCC 2016 